\title{
Increase in Dissolution Rate of Simvastatin by Amorphous Solid Dispersion System with Hydroxypropylmethylcellulose Polymer
}

\author{
ERIZAL ZAINI ${ }^{\star 1}$, ALESSANDRO EVERT $^{2}$ and MARIA DONA OCTAVIA ${ }^{2}$ \\ 1'Department of Pharmaceutics, Faculty of Pharmacy, Andalas University, \\ Padang, West Sumatera Barat, Indonesia. \\ ${ }^{2}$ School of Pharmaceutical Sciences (STIFARM) Padang, West Sumatera, Indonesia. \\ ${ }^{*}$ Corresponding author E-mail: erizal.ffua @ gmail.com \\ http://dx.doi.org/10.13005/ojc/330457
}

(Received: May 24, 2017; Accepted: June 16, 2017)

\begin{abstract}
The objective of the present study was to prepare amorphous solid dispersion system simvastatin-hydroxypropylmethylcellulose (HPMC) to enhance the dissolution rate. Amorphous solid dispersion of simvastatin was prepared by solvent technique using HPMC as carrier with ratio of $1: 1,1: 3$ and $1: 5(\mathrm{w} / \mathrm{w})$. Physicochemical properties of solid dispersions were investigated by X-ray powder diffraction, thermal analysis of differential scanning calorimetry (DSC) and scanning electron microscopy. The dissolution rate profile was performed at $37 \pm 0.5^{\circ} \mathrm{C}$ and $50 \mathrm{rpm}$ in phosphate buffer solution ( $\mathrm{pH} 7$ ) containing $0,5 \%$ sodium laurylsulphate. Powder $\mathrm{X}$-ray diffraction of solid dispersion system exhibited decrease in peak diffraction intensity of simvastatin when increasing the HPMC ratio in solid dispersion system. DSC thermogram of solid dispersion system showed the absence of endothermic peak of simvastatin. All the solid dispersion demonstrated faster dissolution rate in comparison with intact simvastatin and its physical mixture. The dissolution rate of simvastatin from solid dispersion increased with an increased ratio of HPMC polymer. The solid dispersion system of simvastatin with HPMC provide a promising way to improve its dissolution rate.
\end{abstract}

Keywords : simvastatin, HPMC, solid dispersion, dissolution rate.

\section{INTRODUCTION}

Solubility and dissolution rate of active pharmaceutical ingredients which are low in water have become one of the greatest challenges in the development of solid dosage form in pharmaceutical industry. Drugs with low solubility and high permeability, which are classified into BCS class II, will have problems in the absorption process in the gastrointestinal tract, and dissolution is the rate limiting step in absorption process ${ }^{1}$.

Various approaches and strategies to overcome the problem of poorly soluble drugs in water have been conducted. These include salt formation, inclusion complexes, the formation of co-crystal, eutectic mixture and solid dispersion system $^{2-6}$. The technique of solid dispersion system 
is one of the popular techniques to increase the dissolution rate of solid drugs with low solubility in water. Solid dispersion dispersions of one or more active pharmaceutical ingredients in solid carrier whether polymeric or non-polymeric prepared by solvent techniques, melting and combination of both ${ }^{7}$. Pharmaceutical active substance in solid dispersion system may present in the form of crystalline or amorphous phase while the carrier may be in the form of crystalline or amorphous phase $^{8}$. A number of pharmaceutical solid dosage forms in the market have been manufactured in the form of solid dispersion system e.g. itraconazole $\left(\right.$ Sporanox $\left.{ }^{\circledR}\right)$, etravirine (Intelence ${ }^{\circledR}$ ) and griseofulvin $\left(\text { Gris-PEG }{ }^{\circledR}\right)^{7}$.

Simvastatin is a crystalline solid which is practically insoluble in water and its biological availability in the body is low. Simvastatin is used as antihypercholesterolemia and to overcome dyslipidemia. Simvastatin is categorized into BCS class II drug (low solubility and high permeability). The absorption of simvastatin in the gastrointestinal tract is limited by the dissolution rate. Therefore, increase in simvastatin dissolution rate will have a significant impact on the increase of its biological availability and better therapeutic efficacy ${ }^{9,10}$. Hydrophilic polymer is often used as carrier in solid dispersion system, e.g.PVP K-30, PEG 6000 and HPMC. These carriers are preferred because they have high solubility in water, considered as inert for physiological system and low toxicity ${ }^{8}$. HPMC as a popular hydrophilic polymer, has been used to enhance the dissolution rate of many drugs ${ }^{11,12}$.

The purpose of this study was to evaluate the use of HPMC hydrophilic polymer in increasing simvastatin dissolution rate through solid dispersion system using solvent methods.

\section{EXPERIMENTAL}

Simvastatin (Shangyu Jingxin, China), Hydroxypropylmethylcellulose (Shin Etsu, Japan), potassium dihydrogen phosphate (Bratachem, Indonesia), sodium hydroxide (Bratachem, Indonesia), sodium lauryl sulphate (Bratachem, Indonesia), ethanol 96\% (Bratachem, Indonesia), methanol (Bratachem, Indonesia) and distilled water.

\section{Preparation of solid dispersion system}

Simvastatin solid dispersion system was prepared by solvent technique using HPMC as carrier with ratios of $1: 1,1: 3$ and 1:5 $(\mathrm{w} / \mathrm{w})$. The required amount of simvastatin and HPMC were dissolved in ethanol $96 \%$ with the aid of stirring until clear solution was formed. Solvent was evaporated by heating in a vacuum oven at a temperature of $40-50^{\circ} \mathrm{C}$. After drying, solid dispersion system was ground and sieved through mesh 70. As a comparison, physical mixture of simvastatin and HPMC at a ratio of $1: 1$ $w / w$ was prepared by conventional mixing with mortar and pestle.

\section{X-ray diffraction analysis}

The pattern of X-ray diffraction of simvastatin, solid dispersion system and its physical mixture and HPMC were obtained by using X-ray diffractometer of PAN analytical PW 30/40 X-ray. The condition of measuring was as follow: target Cu metal, filter $\mathrm{K} \alpha$, voltage $40 \mathrm{kV}$, current $40 \mathrm{~mA}$, analysis was conducted at a range of 2 theta $10-40^{\circ}$.

\section{Thermal differential scanning calorimetry analysis}

Analysis of differential scanning calorimetric was used to characterize the thermal properties of solid dispersion system and physical mixture. DSC thermogram was obtained by using TA Mettler Toledo FP90 differential scanning calorimeter (Switzerland). A small amount of sample $(5-7 \mathrm{mg})$ was placed in a closed aluminium pan. DSC equipment was programmed at a temperature range of $50-250{ }^{\circ} \mathrm{C}$ with heating speed increase of $10^{\circ} \mathrm{C}$ per minute.

\section{Scanning electron microscope analysis}

The morphology and shape of particles were analyzed using SEM equipment. Sample was placed in an aluminium holder and coated with a thin coat of gold-palladium. Sample was analyzed using HITACHI type S-3400N, Japan. Voltage was adjusted at $20 \mathrm{kV}$ and current of $12 \mathrm{~mA}$. Microphotographs were taken at several magnification.

\section{In vitro dissolution rate studies}

The determination of in vitro dissolution rate profile was conducted by using dissolution testing equipment type I USP (Copley Scientific NE4-COPD, UK). The equipment was adjusted at a speed of 50 
rpm and dissolution medium of phosphate buffer solution ( $\mathrm{pH} 7$ ) containing $0.5 \%$ sodium laurylsulphate of $900 \mathrm{~mL}$. Temperature was maintained at $37^{\circ} \mathrm{C} \pm 0.5^{\circ} \mathrm{C}$. At pre-determined times $(5 ; 10 ; 15$; $30 ; 45$ and 60 minutes), approximately $5 \mathrm{~mL}$ of aliquot were withdrawn and filtered. The concentration ofsimvastatin in medium was determined by UV-Vis spectrophotometer at a maximum absorption wavelength of $238.5 \mathrm{~nm}$. Experiment was conducted in triplicate.

\section{RESULTS AND DISCUSSION}

X-ray diffraction pattern of simvastatin powder and solid dispersion system is shown in Fig.1 Simvastatin is a solid compound which is crystalline in nature, as shown by the X-ray diffractogram pattern which has sharp and characteristic diffraction peaks at 2 theta $\left(^{\circ}\right)=10.7,14.8,15.5,17.3,17.6$, 18.7, 19.3, 22.5 and 28.3.Meanwhile, the X-ray diffraction pattern of HPMC, an amophous solid presented a broad halo without the presence of any diffraction peaks. Diffractogram of physical mixture still showed diffraction peaks from simvastatin crystalline phase even with lower intensity. Solid dispersion system of simvastatin- HPMC (ratios of $1: 1$ ) showed significant decrease in diffraction peaks intensity of simvastatin. This results proved that crystallinity of simvastatin was reduced. However, in solid dispersion 1:3 and 1:5, the diffraction peaks of simvastatin was disappeared.
These results indicated that crystalline phase of simvastatin was transformed into amorphous phase. Simvastatin was dissolved or dispersed homogeneously in molecules or amorphous state in hydrophilic polymer HPMC ${ }^{6,13}$.

Thermal analysis of DSC (Fig.2) gives information on the processes of melting, crystallization, decomposition or change of crystalline phase due to the exposure of heat energy and also to observe interaction of binary system in solid state ${ }^{14}$. DSC thermogram of simvastatin has an endothermic peak at $138.2{ }^{\circ} \mathrm{C}$ which corresponds to the melting point of simvastatin. While DSC thermogram of HPMC does not exhibit an endothermic peak, which indicates that HPMC is an amorphous solid. In the DSC thermogram of solid dispersion and physical mixture, endothermic peak was disappeared. This results confirms the X-ray diffraction data where simvastatin is dispersed in amorphous phase. Therefore, solid dispersion system can modify the degree of crystallinity of drug compound and is an interesting technique in increasing dissolution rate profile $^{15}$.

Microscopic analysis (Fig. 3) with SEM was conducted to observe habit and morphology of solid particles. Simvastatin is present in fine particles with irregular shape, while HPMC has large polygonal shaped particles. In physical mixture powder, we can still distinguish between simvastatin and HPMC

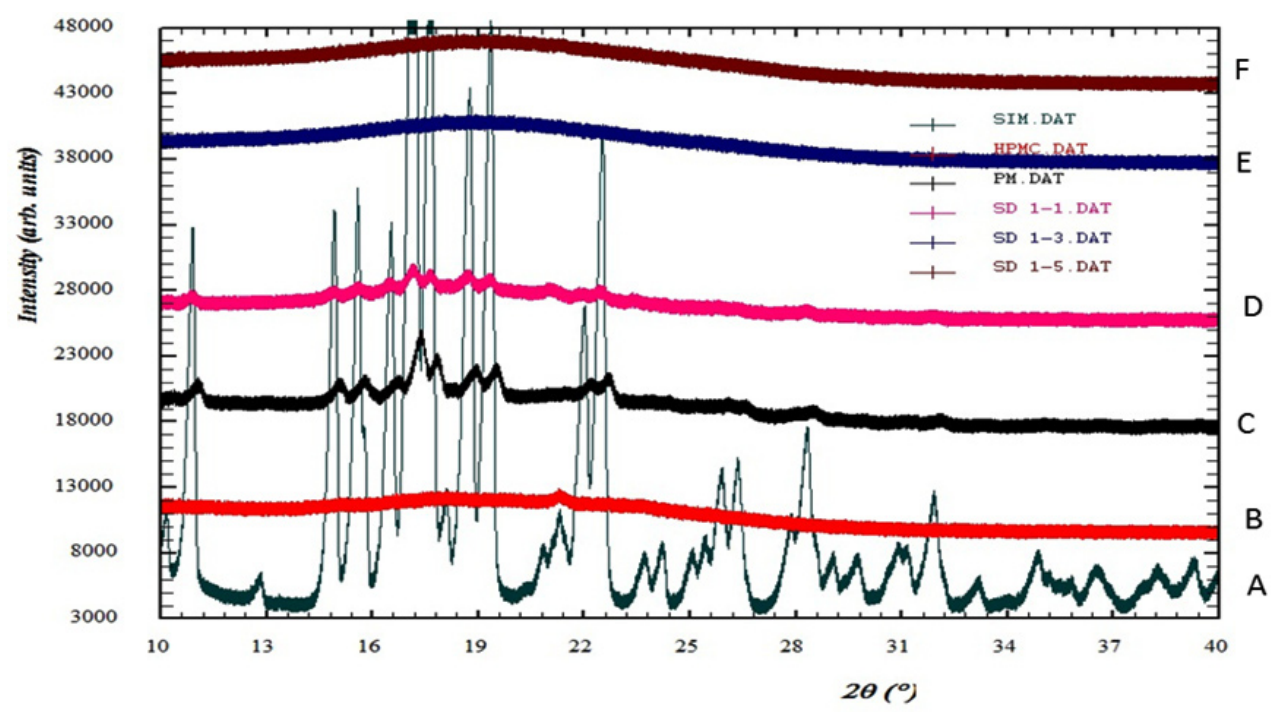

Fig.1: PXRD pattern of A) intact simvastatin, B) HPMC, C) physical mixture, D) solid dispersion 1:1, E) solid dispersion 1:3 and F) solid dispersion 1:5 
particles. In contrast, the microphotograph of solid dispersion system of simvastatin demonstrates homogenous and coherent particles with smooth surface ${ }^{6}$.

Dissolution profile of intact simvastatin, physical mixture and solid dispersion is shown in Fig. 4. Intact simvastatin and its physical mixture showed low dissolution rate in phosphate buffer medium of $\mathrm{pH} 7$ containing sodium laurylsulphate of $0.5 \%$. An amount of $52.94 \%$ intact simvastatin was dissolved in 45 minutes. On the other hand, the dissolution rate of simvastatin from solid dispersion system (ratios of $1: 1,1: 3$ and 1:5) exhibited a significant improvement of dissolution rate within the first 45 minutes, in which approximately $76.01 \%$, $84.69 \%$ and $90.22 \%$ of simvastatin had been dissolved, respectively. As the polymer concentration increased, dissolution rate also increased due to enhanced disaggregation and wettability of simvastatin particles in the presence of hydrophilic polymer. The increase in dissolution rate of simvastatin from solid dispersion system was caused by formation of amorphous phase of simvastatin ${ }^{9}$. The decrease

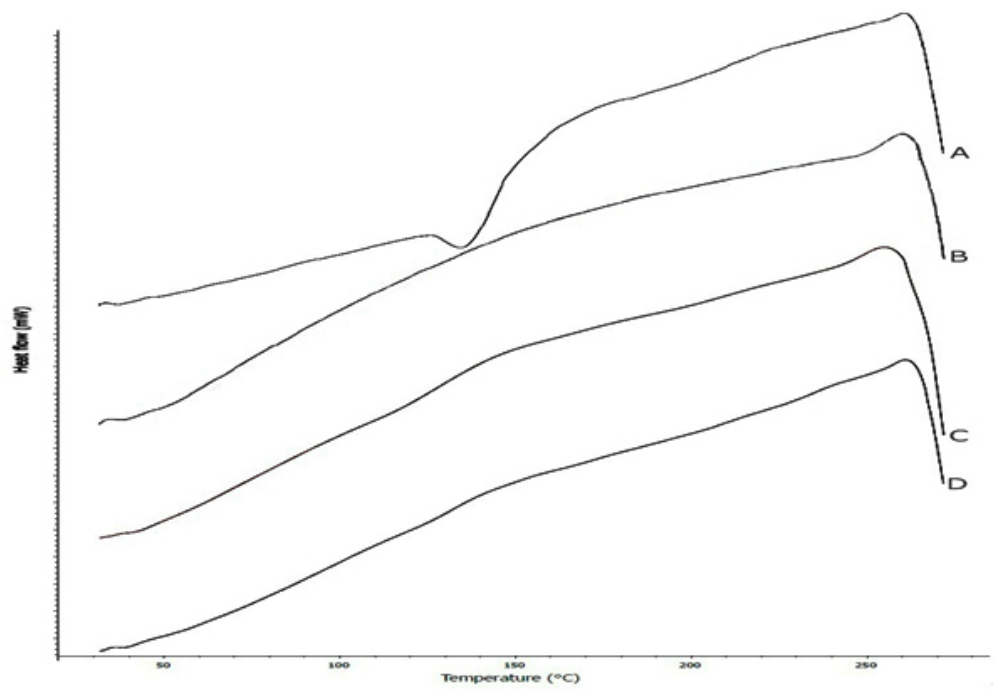

Fig. 2: DSC thermogram of A) intact simvastatin, B) HPMC, C) physical mixture 1:1 and $D$ ) solid dispersion 1:1.
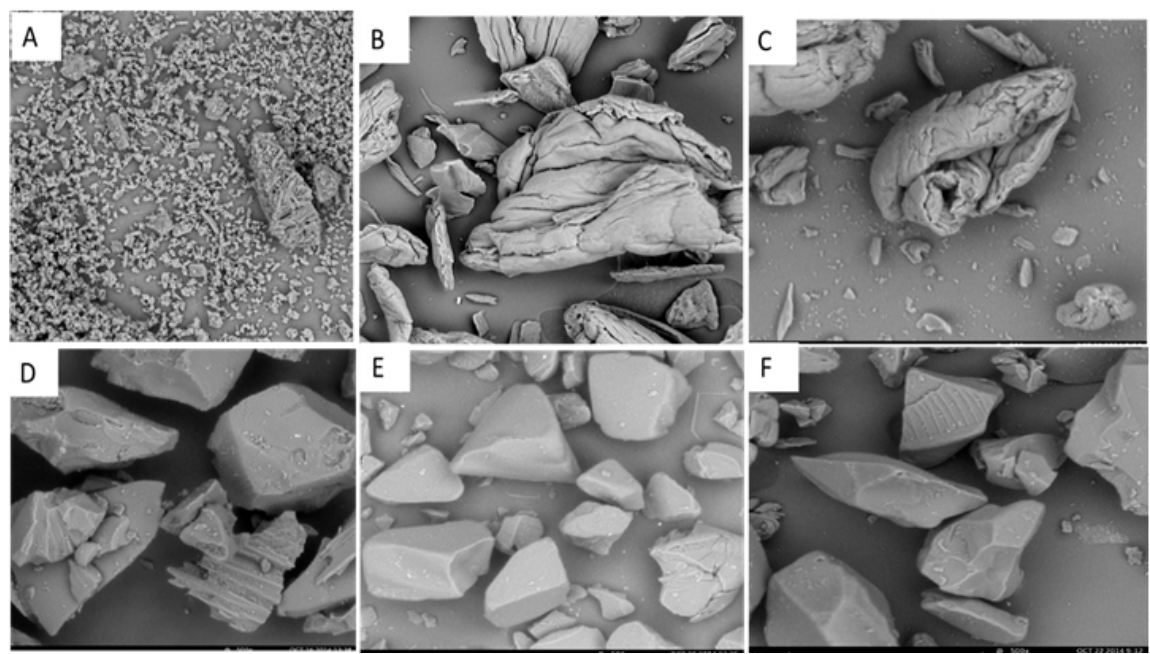

Fig. 3:Scanning electron micrographs of A) intact simvastatin, B) HPMC, C) Physical mixture, D) solid dispersion 1:1, E) solid dispersion 1:3 and F) solid dispersion 1:5.All micrographs were taken at a magnification of $500 \mathrm{x}$ 


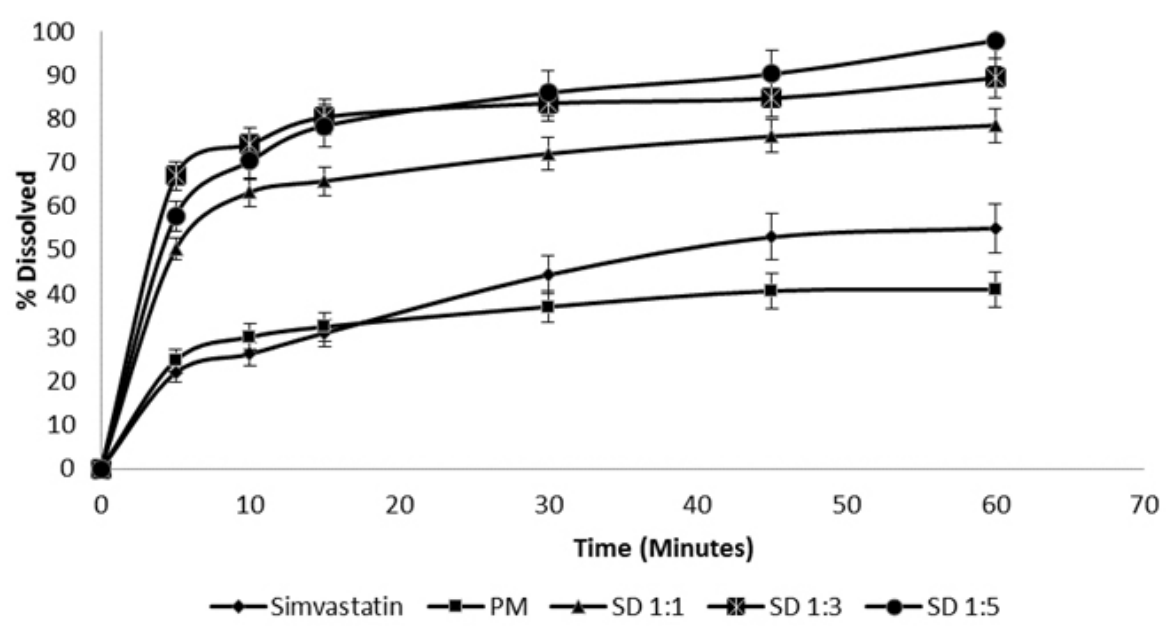

Fig. 4: Dissolution rate profile of intact simvastatin, physical mixture and solid dispersion (1:1, 1:3 and 1:5)

in particle size of simvastatin in HPMC carrier also contributed to increasing the dissolution rate. In addition, lower interfacial tension of dissolution medium by HPMC polymer might also improve the wettability of poorly soluble drugs ${ }^{10,13}$.

\section{CONCLUSION}

Simvastatin solid dispersion system with HPMC hydrophilic polymer can significantly increase dissolution rate of simvastatin compared to intact simvastatin and its physical mixture.

\section{REFERENCES}

1. Kleberg, K.; Jacobsen, J.; Müllertz, A. J. Pharm. Pharmacol. 2010, 62(11), 1656-68.

2. Serajuddin, A.T. Adv. Drug Del. Rev. 2007, 59(7), 603-16.

3. Ezawa, T.; Inoue, Y.; Tunvichien, S.; Suzuki, R.; Kanamoto, I. Int. J. Med. Chem. 2016, 1

4. Hiendrawan, S.; Hartanti, A.W.; Veriansyah, B.; Widjojokusumo, E.; Tjandrawinata, R.R. Int. J. Pharm. Pharm. Sci. 2015, 7(7), 160-4.

5. Zaini, E.; Wahyuni, Y.S.; Halim, A.; Yuliandra, Y. Int. J. Pharm. Sci. Rev. Res. 2015, 35(1), 161-4.

6. Fitriani, L.; Haqi, A.; Zaini, E. J. Adv. Pharm. Tech. Res. 2016, 7(3), 105-9.

7. Janssens, S.; Van den Mooter, G. J. Pharm. Pharmacol. 2009, 61(12), 1571-86.

8. Vasconcelos, T.; Sarmento, B.; Costa, P. Drug Discov. Today. 2007, 12(23), 1068-75.

9. Silva, T.D.; Arantes, V.T.; Resende, J.A.;
Speziali, N.L.; de Oliveira, R.B.; ViannaSoares, C.D. Drug Dev. Ind. Pharm. 2010, 36(11), 1348-55.

10. Rao, M.; Mandage, Y.; Thanki, K.; Bhise, S. Dissol. Tech. 2010, 61, 27-34.

11. Qi, S.; Roser, S.; Edler, KJ.; Pigliacelli, C.; Rogerson, M.; Weuts, I.; Van Dycke, F.; Stokbroekx, S. Pharm. Res. 2013, 30(1), 290302.

12. Oh, M.J.; Shim, J.B.; Yoo, H.; Lee, G.Y.; Jo, H.; Jeong, S.M.; Yuk, S.H.; Lee, D.; Khang, G. Macromol Res. 2012, 20(8), 835-41.

13. Salman, Ardiansyah, Nasrul, E.; Rivai, H.; Ben, E.S.; Zaini, E. Int. J. Pharm. Pharm. Sci. 2014, 7(2), 209-12.

14. Qi, S.; Gryczke, A.; Belton, P.; Craig, D.Q. Int. J. Pharm. 2008, 354(1), 158-67.

15. Mahmoud, E.B. Sci. Pharm. 2011, 79, 37586. 